\title{
Prácticas de maternidad compartida en contexto de encierro: una mirada a la construcción del orden social carcelario
}

Natalia Soledad Ojeda*

\section{Resumen}

El presente artículo constituye una aproximación a los modos que adopta el ejercicio de la maternidad en contexto de encierro carcelario. Estas reflexiones son producto del trabajo de campo etnográfico realizado en un Instituto Correccional de Argentina que aloja mujeres adultas. Se desarrolla a lo largo del texto una mirada original acerca de la construcción del orden social carcelario, a partir de la comprensión de los discursos y las prácticas de las detenidas respecto de su maternidad: sentidos tradicionales y hegemónicos se suman a prácticas de maternidad compartida, como una forma específica de ser "buena madre" al interior del presidio, diseminando las responsabilidades, los valores y las acciones individuales en compromisos compartidos; potenciando de esta manera el rol social de la maternidad.

\section{Palabras clave}

Mujeres. Prisión. Maternidad compartida.

\section{Resumo}

0 presente artigo constitui uma aproximação aos modos que adota o exercício da maternidade em um contexto de encerro carcerário. Estas reflexões são produto do trabalho de campo etnográfico realizado em um Instituto Correcional da Argentina, que aloja mulheres adultas. Desenvolve-se ao longo do texto, uma visão original acerca da construção da ordem social carcerária, a partir da compreensão dos discursos e das práticas das detentas à respeito de sua maternidade: sentidos tradicionais e hegemônicos se somam à prática de maternidade compartilhada, como uma forma específica de ser "boa mãe" ao interior do presídio, disseminando as responsabilidades, os valores e as ações individuais em compromissos compartilhados; potencializando dessa forma a função social da maternidade

\section{Palavras-chave}

Mulher. Prisão. Maternidade compartilhada.

\footnotetext{
* Natalia é doutora em Antropología Social e investigadora asistente del Consejo Nacional de Investigaciones Científicas y Técnicas / Universidad Nacional del Centro de la Provincia de Buenos Aires. E-mail: natalyaojeda@gmail.com.
} 


\section{Abstract}

This paper is approaches the forms adopted by the exercise of motherhood in the context of prison confinement. These reflections are the result of ethnographic fieldwork conducted in an Argentine Correctional Institution that houses adult women. An original look about the construction of the social order in prison is developed along this article. The focus lays on the discourses and practices of prisoners regarding their motherhood, and how traditional and hegemonic senses are added to shared motherhood practices as a specific way of being a "good mother" inside prison. Responsibilities, values and individual actions on shared commitments are spread and, thus, the social role of motherhood is potentiated.

\section{Keywords}

Woman. Jail. Shared motherhood.

\section{Introducción}

Los datos que sustentan el desarrollo del artículo forman parte del proyecto de investigación doctoral que planteó como objetivo general, dar cuenta de la complejidad y los sentidos del rol de la maternidad en contexto de encierro. Los mismos se rastrearon en una cárcel de mujeres perteneciente al Servicio Penitenciario Federal Argentino (SPF), ubicada en el interior del país ${ }^{1}$.

Más específicamente, la necesidad del análisis de la maternidad en este contexto emergió a partir de la experiencia de trabajo de campo etnográfico (2010 - 2012) que mostró el lugar central que las reclusas, mediante sus discursos y sus prácticas, daban a sus hijos. Se develó así la construcción del orden social carcelario. En este sentido, la maternidad se presentó como una matriz de imágenes, significados, prácticas y sentimientos (...) social y culturalmente producidos (SCHERPER-HUGHES, 1997, p.329) que daba forma, es este caso, a las sociabilidades carcelarias y ciertas jerarquías internas.

Desde esta mirada, se entiende a la cárcel como un tipo particular de ordenamiento social (FOUCAULT, 1992), de espacio de la administración del Estado pero, también de lugar del castigo y la pena (TISCORNIA, 2004).

\footnotetext{
${ }^{1}$ Establecimiento carcelario ubicado a unos 600 kilómetros de distancia de la Ciudad de Buenos Aires.
} 
Espacio que se redefine constantemente a partir de las relaciones sociales complejas que lo constituyen. El caso del ejercicio de la maternidad en prisión ilustra este razonamiento.

El presente artículo ofrece una descripción etnográfica sobre esta problemática a los efectos de descubrir parte del funcionamiento real de un establecimiento penitenciario de mujeresylas formas particularesy específicas, que en este caso, adopta la construcción del orden social carcelario. Desde esta perspectiva, el artículo se encuentra estructurado en cuatro partes: en primer lugar, y tras describir los aspectos metodológicos, se presenta a las mujeres privadas de la libertad. Luego, se identifican sus discursos sobre la maternidad y las consecuencias de los mismos en la generación de jerarquías internas y en sus relaciones con las agentes penitenciarias. Discursos estos asociados a los sentidos tradicionales o hegemónicos de la maternidad. Posteriormente, se trabaja el caso de la maternidad "compartida" que, en tanto forma específica del ejercicio de la maternidad en contextos de encierro, brinda nuevas y alternativas formas de ser madre, al tiempo que refuerza cierto modelo ejemplar de maternidad esclareciendo el lugar destacado en el proceso de construcción del orden social carcelario. Para finalizar, se valora el análisis del ejercicio de la maternidad intramuros, como forma de advertir la complejidad del fenómeno del encierro.

\section{Aspectos metodológicos}

Con el objetivo de recoger los datos, se ha utilizado la observación participante como la principal herramienta para documentar la vida en prisión. Este instrumento fue efectivo para dar a conocer las formas cotidianas de interacción en el mundo de las detenidas y sus relaciones con las agentes penitenciarias. A su vez, la observación participante fue complementada con la revisión de numerosa documentación que circula por las unidades carcelarias (estadísticas oficiales, legajos sociales, judiciales, criminológicos y médicos; oficios judiciales e informes producidos por las áreas técnicas de tratamiento: educación, trabajo, asistencia médica, etc.).

El trabajo de campo en esta cárcel fue autorizado por la Dirección Nacional (DN) del Servicio Penitenciario Federal Argentino (SPF). El mismo contempló el acceso en cada espacio de la unidad penitenciaria donde se tomaron diversos registros de campo: oficinas de celadoras, oficinas de las áreas técnicas de tratamiento, puertas de ingresos a los pabellones, interior de los pabellones, 
espacios de recreación como patios y salón de usos múltiples. Asimismo, el permiso otorgado por la DN posibilitó el acceso a documentos oficiales.

\section{Un breve contexto explicativo sobre las mujeres privadas de la libertad}

La reclusión penal de mujeres ha sido un tema poco abordado desde las ciencias sociales. Quienes se interesaron en él lo han hecho principalmente desde las experiencias en cárceles masculinas, generalizando desde allí sus conclusiones al conjunto. De esta manera, han pasado por alto las particularidades y las diferencias, que de hecho, existen entre las experiencias de detención de varones y de mujeres. De aquí la necesidad de complementar el conocimiento y el estudio de los sistemas penitenciarios desde la descripción de las experiencias de reclusión de las mujeres.

El sistema punitivo moderno nace en las últimas décadas del siglo XIX en el marco del desarrollo y consolidación de los Estados modernos. En Argentina, los proyectos de modernización del castigo estaban dirigidos a la población masculina, motivo por el cual el encierro femenino estuvo delegado exclusivamente a órdenes religiosas y organizaciones caritativas (CAIMARI, 2007). Entre las causas que explican los motivos de esta decisión estatal se encuentra la distinción en la calificación de los delitos cometidos por las mujeres, los que se consideraban menores (acusación de brujería, pequeños hurtos, mujeres reacias a la autoridad familiar) y cuyo reencauzamiento debía centrarse en la labor doméstica y los buenos hábitos. Por lo tanto, consideraban que las mujeres criminales necesitaban un ambiente amoroso y maternal (SÁNCHEZ ISNARDI et al., 2011), específicamente a cargo de monjas en el llamado Asilo Correccional de Mujeres².

Desde finales del siglo XIX y por más de ochenta años, las mujeres continuaron a cargo de órdenes religiosas. Fue en el año de 1974, cuando dichas órdenes dejan la administración de la cárcel de mujeres para que pasen a formar parte de la jurisdicción del Servicio Penitenciario. Al respecto Lila Caimari (2007) plantea:

\footnotetext{
${ }^{2}$ Lugar ubicado en el barrio de San Telmo, de la Ciudad Autónoma de Buenos Aires, donde hoy funciona el Museo Penitenciario y la Academia Superior de Estudios Penitenciarios.
} 
La continuidad en el abordaje (o no abordaje) de la cuestión carcelaria femenina fue posible porque esta población no era percibida como una amenaza importante al orden establecido. El cambio de esta política (o ausencia de política) -tardío y abruptoestuvo vinculado a la llegada de una nueva población de mujeres a las prisiones argentinas. A principios de la década de 1970, centenares de jóvenes acusadas de actividades políticas subversivas inundaron las cárceles del Buen Pastor, cambiando por completo su fisonomía. Esta agitada coyuntura política coincidía con un cambio de dirección en los proyectos de la congregación, cuyas autoridades deseaban desentenderse de sus responsabilidades en las cárceles latinoamericanas, negándose a ser vehículo de las políticas autoritarias de regímenes que condenaban. En poquísimo tiempo, las cárceles de mujeres pasaron a control estatal (2007, p.17).

Con la conformación de una cárcel de mujeres propiamente dicha, se crea el espacio físico y exclusivo para su alojamiento en manos del Estado. Sin embargo, todo parece indicar que, por lo menos hasta mediados de los años 80 , la conformación principal de la población penal femenina, estuvo compuesta por presas políticas, en su mayoría trasladadas de la cárcel de Villa Devoto al penal de Ezeiza en el año de 1983 (D’ANTONIO, 2011).

Por lo tanto, la reclusión penal de mujeres es un hecho de la historia reciente. Como veremos, en Argentina, y en muchos países de América Latina, solo a partir de los años 90 la cárcel de mujeres tomó la forma que conocemos hoy: aumento constante de la población penal de ciertos sectores socioeconómicos que se vinculan al delito a través de la comercialización y el trasporte de drogas (PALMA CAMPOS, 2011; KALINSKY, 2006). En consecuencia, es en este periodo histórico que la población penal pasó de estar compuesta principalmente por presas políticas a estar conformada por "presas comunes".

Las detenidas en la unidad penitenciaria bajo análisis, componen un sector joven de la población penal: 50 mujeres de entre 25 y 45 años de sectores socioeconómicos bajos, escasamente escolarizadas, que han sufrido violencia previa a la detención, como abuso sexual y/o violencia de género ${ }^{3}$. El $85 \%$ de las mujeres allí alojadas lo están por causas menores vinculadas

\footnotetext{
${ }^{3}$ Datos obrantes en legajos sociales de las detenidas. Además surgen en entrevistas realizadas a las trabajadoras sociales de esta cárcel.
} 
a las drogas ${ }^{4}$. Otras por delitos de homicidios, clásicamente denominados como "pasionales" e infanticidio. Por último, algunas están detenidas por delitos contra la propiedad.

La criminología feminista (SIMPSON, 1990; SMART, 1994) señaló que las mujeres encarceladas han cometido un doble desvío: de la ley y, al mismo tiempo, de su rol genérico que las asocia a determinadas responsabilidades familiares, especialmente a la crianza de los hijos. Las mujeres privadas de la libertad no son ajenas a los supuestos de buena parte de nuestra sociedad que piensa a la maternidad como vocación natural de las mujeres (MORENO, 2000; KALINSKY Y CAÑETE, 2010) esencializando así una relación social (LAMA, 1986; NARI, 2004). Estos supuestos, penetran los muros de las prisiones donde además se reafirman de una manera singular y novedosa: son adoptados por las detenidas pero, a la vez, son redefinidos a partir de las particularidades propias del contexto de encierro.

El desvío de su rol de género, a pesar de ser señalado y castigado, es reencausado en muchos de sus discursos como prueba y justificación de los delitos cometidos: por ser buenas madres y haber dado todo por sus hijos se encuentran en prisión. Pero, a su vez, esta voluntad, expresada en sus discursos, por mostrarse "buenas madres", adhiriendo a una concepción hegemónica sobre la maternidad, se desarrolla a la par de nuevas experiencias de ser madres. Así es como el encierro pone en evidencia prácticas de una maternidad compartida donde los sentidos más tradicionales y hegemónicos sobre esta práctica se conjugan con sentidos alternativos propios del contexto carcelario para dar forma a cierto ordenamiento social intramuros.

\section{La justificación moral de los delitos cometidos}

De las cincuenta detenidas en esta cárcel, cuarenta y nueve eran madres. Dada la pequeña instalación disponible para albergar a mujeres con hijos, solo dos de ellas tenían la posibilidad de permanecer allí junto a los niños ${ }^{5}$.

\footnotetext{
${ }^{4}$ Las causas principalmente eran transporte de drogas en zonas de frontera o venta al menudeo

${ }^{5}$ La ley argentina prevé la posibilidad de que las mujeres presas conserven a sus hijos hasta los cuatro años de edad. Además señala que el alojamiento de estas mujeres se debe concretar en espacios separados del resto de la población penal. Se denomina planta de madres a estos espacios que según la Unidad Penitenciaria, pueden tener más o menos capacidad de alojamiento. En esta Unidad Carcelaria la planta de madres podía alojar hasta dos mujeres con sus respectivos hijos.
} 
El resto de las detenidas se encontraba a cientos de kilómetros de distancia de ellos.

El foco puesto en la maternidad proviene de la insistencia de estas mujeres de saberse, reconocerse y darse a conocer como "madres" en primer plano. En conversaciones informales, en entrevistas y en diversas actividades institucionales ${ }^{6}$, la gran mayoría de las detenidas evaluaba su estadía carcelaria como consecuencia de haber dado todo por sus hijos. Asimismo, este hecho las posicionaba de mejor o peor manera dentro de la escala social carcelaria, ya que detenidas y personal penitenciario valoraban los delitos de acuerdo con el grado de "compromiso" con sus hijos. Así, aquellas que habían asesinado a quien maltrataba o abusaba de sus hijos eran bien vistas y conservaban el respeto de las demás mujeres intramuros. En el extremo opuesto se encontraban las "infantas". Es decir, la denominación nativa para referirse a quienes habían matado a sus propios hijos. Ellas carecían de toda estimación posible. Sin embargo, todas ellas, incluso las detenidas que se encontraban presas por delitos más simples (como delitos menores vinculados a las drogas) también activaban la estrategia de ser madres a la hora de justificar su ingreso al mundo delictivo.

Como bien lo planteaba una de ellas,

"Sufro porque ni siquiera puedo hablar por teléfono con ellos. A veces llamo para escuchar sus voces pero enseguida el padre agarra el teléfono y sabe que soy yo. Me insulta. Él dice que abandoné a mis hijos, que no soy una buena madre. Recuerdo la última vez que me fui de casa y dejé a Joni con tres años. Era bebé y me miraba mientras me iba. Yo no quería irme. Pero tuve que hacerlo. Mi marido tampoco me pidió que me quedara. Nuca más volví a verlo. (Julieta, Detenida, 29 años)”.

El hecho de no ser "buenas madres" y de no estar en el lugar que suponían les corresponde podía llegar a generarles todo tipo de malestar, teniendo en cuenta además que en el espacio donde se encontraban las evaluaciones morales, sobre el ser buena o mala madre, estaban a la orden del día.

El delito las llevó a la prisión y, por lo tanto, las llevó lejos de sus hijos, aparece entonces "la expresión obligatoria de los sentimientos" (Mauss, 1979) que,

\footnotetext{
${ }^{6}$ Talleres de trabajo, actividades de recreación como yoga o danzas y fiestas por el inicio o cierre del ciclo lectivo.
} 
en tanto deber moral, reordena el mandato social que las destinaba junto a sus maridos e hijos al seno del hogar. Tal es así que están en la cárcel cumpliendo una condena, pero no por cualquier motivo sino por haber defendido (y entregado hasta la libertad) por el amparo y el cuidado de sus hijos, lo que les reintegra algo del sentido que les permite continuar siendo lo que ellas consideran una "buena madre".

Así, traficar o transportar drogas, prostituirse o manejar pequeñas redes de prostitución, robar o matar, se convertían en una salida para defender y proteger a sus hijos: "solo busqué darle todo a mis hijos", "fue para darles de comer", "maté para protegerlos". En muchos casos, algunos de los delitos cometidos las convertían en una especie de heroína respetada por detenidas y por agentes penitenciarias.

Por ejemplo, era el caso de aquellas internas que se encontraban pagando una pena por matar a sus parejas, quienes habrían abusado o golpeado a sus hijos. En este sentido, si bien todas habían cometido delitos con el objetivo de salvaguardar a sus hijos, lo cierto era que había delitos que, a los ojos de las demás, eran justificados y reconocidos como más válidos, por la manera en que evidenciaban la relación de protección que la madre había tenido con sus hijos. Así lo ilustra el diálogo entre dos celadoras:

“Gómez está por matar a la pareja. Parece que el tipo abusaba de la hija más grandecita de ella. Y bueno... la mina lo mató. No quiero verme en esa situación, pero si te tocan una hija ¿quién no haría lo mismo?".

[Josefina, Celadora, 45 años].

Yo recién ingresaba al servicio. Entonces, llenando la ficha de ingreso de una interna, le pregunté como a todas: ‘Causa?'. Ella me dice: 'Homicidio agravado por el vínculo'. Me mira a los ojos y, entre dientes, la escucho decir: 'Abusaba de mi hija'. 'Bien hecho', contesté.

[Griselda, Celadora, 55años].

Las evaluaciones morales sobre los delitos configuran relaciones de mayor o menor afinidad entre las internas y el personal penitenciario. Pero también dan lugar a ordenamientos internos entre las detenidas. En primer lugar, en cuanto a la construcción del orden social carcelario, nos encontramos con la causa judicial. Los delitos cometidos ubican a estas mujeres en posiciones determinadas en la escala social carcelaria. Robar y "poner el pecho" para darle de comer a los hijos, matar para protegerlos o vengarlos, indica la 
dificultad en la que se encontraban estas mujeres. Así aquello que han inscripto los jueces en sus sentencias funciona como un primer ordenador de este mundo social.

En segundo lugar, se trata del discurso autojustificador. Incluso en caso de detenidas por delito vinculados a las drogas o felicidio ${ }^{7}$. Una mujer, presa por el homicidio de un hijo, explica el supuesto desapego con otro hijo recién nacido intramuros, como el resultado de no encariñarse con él: ¿Cómo aferrarme a alguien, si sé que en 4 años se va? ¿Qué hago en ese momento...? Prefiero la separación. Si él está bien afuera, yo estoy bien adentro". Entonces, más allá de este primer ordenador que informa, a través de una sentencia judicial, sobre el delito cometido por estas mujeres, ellas reencausan los sentidos hegemónicos de la maternidad indicando que a pesar de haber matado a su hijo/a ellas podían ser buenas madres de otros hijos e incluso del propio niño muerto. Se destacan casos en que las mujeres explican que han matado a su hijo para "no verlo sufrir". Esto no significa que todas las mujeres puedan hacer efectivo el discurso autojustificador. De hecho, muchas de aquellas que se encuentran presas por el homicidio de sus hijos prefieren no hablar del tema y soportar ser objeto de críticas y represalias. Otras mujeres a pesar de sus discursos tampoco logran sostener este ideal de "buenas madre" que refuerza el encierro. En una oportunidad un bebe murió por la noche aplastado por el cuerpo de su madre y su compañera de encierro, quienes bajo los efectos de las drogas, se durmieron y sin quererlo dieron muerte al bebe. Las mujeres que participaron de este incidente fueron culpabilizadas por todas (detenidas y personal) y señaladas como malas madres. Estos casos, hacen evidente cómo, en el contexto de encierro, se refuerza la responsabilidad genérica femenina, revalidando relaciones de desigualdad preexistentes a la detención.

En consecuencia, la maternidad en prisión se presenta como un conjunto de predisposiciones culturales que, habiendo sido tomadas y aprehendidas en el marco de una historicidad determinada, crean, modelan y sustentan ciertas clases de relaciones entre grupos y personas. Estas mujeres, que han

\footnotetext{
${ }^{7}$ Definido como "casos en que una madre ejerce violencia (letal o daños graves) sobre sus hijos, ya sea en el momento del nacimiento o hasta los cinco años aproximadamente (infanticidio)" (Kalinsky 2007, p.2).

${ }^{8}$ Se trata de casos en que los niños padecían enfermedades terminales o también casos en que la mujer junto a sus hijos se veían envueltos en altos grados de violencia por parte de las parejas masculinas.
} 
sido criminalizadas por su transgresión a ciertas normas legales, persiguen el imperativo moral mayor de "ser buenas madres". Algunas lo logran, otra no. Aunque siempre opera el señalamiento (junto a expresiones de violencia) que permite mantener cierto control social sobre las mujeres sospechadas de ser transgresoras de este orden moral asociado a la maternidad.

Siguiendo a Durkheim (1993), podemos comprender la adhesión, cuando los actos ejecutados en conformidad con la regla moral son alabados, siendo que quienes los realizan son honrados por la comunidad de la que forman parte. De aquí la gran estimación de la población penal en general, y de las agentes penitenciarias en particular, hacia aquellas mujeres que han matado a quienes abusaron de sus hijos. El crimen, en este caso, se justifica en nombre del imperativo que indica el deber de una madre de proteger y dar todo por los hijos. Sin embargo, el trabajo de campo ha mostrado que, en prisión, este imperativo (que podría generalizarse a toda nuestra sociedad) adquiere mayor profundidad en tanto los conflictos generados en torno a ser o no ser "buena madre" llevan, al aprecio de algunas y al desprecio de otras. Es por eso que, en prisión, esta norma moral se activa como estrategia, al decir de Zigon (2007) como "táctica ética", movilizada por las detenidas en un momento de quiebre como lo es la privación de la libertad (ver también NOEL, 2011).

\section{Maternidad compartida}

Los niños que han podido permanecer junto a sus madres en prisión (dada la posibilidad que habilita la ley de ejecución de la pena privativa de la libertad en su artículo $195^{\circ}$ ) se convierten en actores importantes intramuros. Son requeridos y objetos de variadas disputas y enfrentamientos. La Planta de Madres de esta unidad es muy pequeña y solo albergaba a dos madres con sus respectivos hijos. Por ello, nunca hubo más que dos o tres niños en esta planta. Ellos fueron cambiando a lo largo del trabajo de campo, pero la atención y los cuidados que se ponían en ellos eran los mismos. La crianza compartida: una madre y muchas tías formaban parte de la realidad de los bebés y de los niños en esta cárcel.

Era común que la llegada de un bebé a la unidad conmoviera. Todas querían conocer al bebé, todas querían tocarlo o llevarlo en brazos, y todas querían colaborar, en alguna medida, de sus cuidados: conseguir ropas y quienes recibían visitas pedían a sus familiares diferentes elementos 
posiblemente útiles. Todas disputaban la presencia de los bebés y los niños en pabellones o en el patio, con muestras de afecto y de cariño. Es interesante el modo en que las mujeres que conviven junto a sus madres son presentadas a los bebés y los niños: son las tías. El rol que les toca, como "tías", es el del juego, los mimos y los cuidados compartidos. En todos los casos, las muestras de afecto con los niños se destacan: besos, caricias, abrazos y juegos forman parte de los recursos que ponen en funcionamiento estas mujeres para con los niños de otras detenidas.

En algunos casos, la convivencia en la planta de madres, evidenciaba cómo las mujeres compartían las responsabilidades de ambos niños: vigilarlos en el juego, mientras la otra preparaba la leche, cocinaba o lavaba, o cambiar pañales y bañar a ambos niños. Esto no quería decir que la convivencia siempre fuera pacífica ni que se criara a ambos niños de común acuerdo. De hecho, hubo casos en que las peleas entre niños, por algún juguete por ejemplo, derivaban en fuertes agresiones físicas entre las internas. O también, casos en que una de las madres consideraba que la otra no "cuidaba" bien a su hijo, por lo cual asumía ella la responsabilidad por el otro bebé. Tal fue el caso de Rosa (25 años) y Liliana (30 años), dos detenidas que compartían convivencia en la planta de madres. Una tarde Liliana mientras cuidaba a ambos niños en el patio se quejó de Rosa por la forma en que ella consideraba que descuidaba a su hijo:

"A Luki le hago la leche yo, lo baño yo, yo le lavo la ropa. Rosa lo tiene ahí todo sucio. No tiene juguetes. Y bueno... ¿qué voy a hacer? No lo puedo ver así. No lo hago por la madre, lo hago por el nene. De última si preparo una mamadera ¿qué me cuesta preparar dos?”. [Liliana, detenida].

Por fuera de la Planta de Madres, también había acuerdos entre las internas para criar a los niños: lavar y secar sus ropas, planchar, dar la mamadera, jugar. En algunos casos, estos eran favores que se hacían y que se devolvían cuando la otra quedaba embarazada, en caso de que eso sucediera. El resto decía hacerlo por los niños y, también, para ayudar a sus amigas que habían abandonado por un tiempo el pabellón y que ahora se encontraban en la Planta de Madres. Es decir, que la crianza compartida afianzaba, como base, las relaciones de solidaridades y alianzas preexistentes.

Por un lado, se encontraban las tías internas. Pero, por otro lado, estaban las tías penitenciarias. En esta cárcel, los niños llamaban "tías” a todas las mujeres que reconocían como tales y con las que tenían cierta intimidad, 
es decir, a aquellas que veían a diario, sin distinguir, en principio, entre internas y personal. En esta cárcel, el acercamiento entre los niños y las agentes penitenciarias nunca fue menor. Las celadoras solían circular con ellos en brazos por los pasillos y, muchas veces, entraban también con ellas a determinados pabellones, lugar en el que se encontraban con el resto de las internas. Tanto internas como agentes compartían la idea de que la crianza de los chicos en esta cárcel era totalmente diferente de lo que podía ser en una unidad de máxima seguridad o en una unidad dedicada al alojamiento exclusivo de mujeres embarazadas y con hijos, como puede ser la Unidad 31 de Ezeiza (que como esta cárcel también pertenece al SPF).

Muchas celadoras y responsables por la seguridad del penal, venían de trabajar por años en esta unidad de Buenos Aires, que aloja en un sector a madres con hijos porque tiene la infraestructura necesaria para contenerlos (servicio médico especializado en pediatría, jardín maternal y de infantes, salón de juegos, etc.). Las experiencias de internas y de agentes en la Unidad 31 de Ezeiza, respecto de la relación con los chicos, parecen ser bien diferentes de lo que ocurre en esta cárcel del interior del país. Las agentes penitenciarias planteaban: "Se creen que porque tienen hijos pueden hacer lo que quieren. Que no te sorprenda que se queden embarazadas a propósito. Ellas usan a sus hijos" (Margarita, Celadora, 48 años). Y, sobre sus relaciones con los niños, dicen que no podían tocarlos y que cualquier acercamiento a los chicos podía ser usado en su contra: "No los podés tocar porque las madres enseguida te van a denunciar que los golpeaste o cosas así. Mejor, tenerlos lejos".

Por otro lado, las internas destacaban la falta de sensibilidad de las celadoras que trabajaban en las mencionadas unidades de Buenos Aires. Una interna relataba, con lágrimas en los ojos, su experiencia como madre en la unidad 31: “¿Sabes cómo les llaman a los chicos? Los chorritos. ¿A vos te parece? ¿Qué culpa tienen ellos de los delitos que cometimos nosotras?”. Lo que llama la atención es que esas mujeres penitenciarias, que en la unidad 31, llamaban "chorritos" a los niños y que, a su vez, eran llamadas por los niños "Chela" (en lugar de "Cela"), son las mismas mujeres que hoy trabajan en esta cárcel y que, en este contexto, parecen permitirse tener en brazos a los niños, hacerles caricias y ser consideradas por ellos "una tía". En este sentido, también ellas hacen parte de la crianza de los niños.

Así es que principio, las palabras que más rápido aprendían los chicos en esta unidad eran mamá y tía. Estas mujeres, en mayor o menor medida, hacían de la maternidad en prisión una maternidad compartida. En su tesis 
de maestría, María Augusta Montalvo Cepeda (2007), a partir de un trabajo de campo en una prisión de mujeres en Ecuador, encuentra y describe, en forma positiva, la experiencia de la maternidad, también entendida como compartida o colectiva:

"El ejercicio de la maternidad en la cárcel adquiere otro significado porque son mujeres-madres que, a pesar de responder a los parámetros sociales establecidos, en su cotidianidad los sortean y construyen lazos entre mujeres para dar paso a maternidades colectivas. Maternidades que significan confiar en las otras, sentirse apoyadas, distribuir tareas, repartir tiempos y reconocer que, pese a las diferencias en sus maternidades, éstas no son únicas" (2007, p.29).

Principalmente, esta característica de la maternidad colectiva en el encierro rompería con el modelo tradicional de maternidad que la asociaba a una experiencia pasiva e individual. Aparece entonces lo que la autora, desde una perspectiva distinta a la planteada por la mirada androcéntrica, llama "el ejercicio político de la maternidad". La experiencia de maternidades en mujeres pertenecientes a pueblos indígenas también puede aportar algo de luz respecto de los sentidos que tiene, dentro de una comunidad, la maternidad compartida. Silvia Hirsch y Marcela Amador Ospina (2011) plantean que a las mujeres guaraníes sus relatos sobre la maternidad les permite evaluar que la misma no se constituye solo como una práctica individual asignada exclusivamente a las madres biológicas, sino que es compartida por las demás mujeres de la familia extensa. Así, la presencia de hermanas, de tías y de abuelas juega un papel fundamental en la crianza de las niñas y los niños. Por una parte, los niños desarrollan fuertes vínculos afectivos con otras mujeres que se ocupan de ellos y, por otra, el apoyo en este cuidado compartido permite a las madres ausentarse de sus hogares, realizar tareas agrícolas, laborales y educativas, fuera del espacio doméstico.

También la maternidad compartida dentro de esta prisión hace su sentido. El cansancio de las madres era paliado por la crianza conjunta entre detenidas y, en este caso además, con la no infrecuente aparición de la ayuda y de la presencia de las agentes penitenciarias. Más de 100 brazos que sabían cambiar pañales y preparar mamaderas estaban dispuestos cuando las madres o los niños así lo necesitaban. Pero lo interesante es que las internas que no tenían la posibilidad de tener a sus hijos con ellas mostraban sus habilidades maternales al momento de cuidar a los hijos de otras detenidas. Jorgelina, 
habitualmente, levantaba en sus brazos al hijo de Irma y caminaba con él por las tarde en el patio, y repetía: "vieron cómo con la tía no llora".

La presencia de los niños les facilitaba a las internas mostrar sus aptitudes de "buenas madres". Mientras tanto, para algunas mujeres, esta maternidad en el encierro les era más grata que otras experiencias en el exterior donde, por ejemplo, cuando debían "acomodar" su cuerpo, durante los días posteriores al parto (en situación de puerperio), no podían descuidar al resto de sus hijos, ni a su pareja masculina. Por el contrario, la maternidad en el encierro, una situación nada ideal, permitía, paradójicamente, el descanso (antes desconocido), al tiempo que permitía a las demás detenidas mostrar, públicamente, sus habilidades maternales y reafirmar, por otra vía, sus discursos que las pintaban como madres abnegadas que lo dan todo por los hijos, a los que saben cuidar y dar amor.

La práctica de una maternidad compartida, y por lo tanto alternativa a la ya conocida, se producía a la par de sentidos tradicionales atribuidos a la misma. Esta doble, y para ellas no contradictoria, forma de ejercer su maternidad en el encierro, les permitía disputar a los bebés y niños que circulaban por la unidad, con el objeto de jerarquizarse como madres y demostrar en la práctica (más allá de los discursos) sus habilidades maternales. De esta manera, se posicionaban y luchaban por un lugar de reconocimiento dentro del entramado social carcelario donde decir y demostrar ser una "buena madre" era sumamente valorado. Como contraparte fracasar en ese intento, complicaba la estadía y convivencia de las mujeres en esta cárcel: las peleas verbales o físicas, la soledad, las represalias o burlas de otras detenidas, no ser oídas por el personal penitenciario, no ser lo suficientemente atendidas por el personal profesional del establecimiento carcelario, entre otras dificultades. De ahí los esfuerzos y el empeño para con los hijos de otras detenidas.

\section{Consideraciones finales}

Las mujeres en prisión apelan a los sentidos tradicionales de nuestra sociedad que asocian a las mujeres con la vocación natural por ser madres y, más que eso, por ser "buenas madres". Así, pese a ser castigadas por haber incumplido su rol más fuerte y elemental, las mujeres privadas de libertad, encausan los sentidos del castigo y sostienen que están encarceladas por ser, justamente, "buenas madres", quienes lo han dado todo por sus hijos: han matado, robado o traficado droga en su nombre. Incluso, las llamadas "infantas" también se 
definen como "buenas madres".

Esto les permite jerarquizarse (o estigmatizarse, si fracasan) y tener una mejor (o peor) estadía carcelaria. Así el primer elemento en la construcción del orden social carcelario de las mujeres, es el impuesto por la sentencia de la causa que ha dado un juez, que se convierte en la herramienta inicial que permite la evaluación entre detenidas y, a su vez, del personal penitenciario hacia estas.

Según estas "sentencias" comienzan a ubicarse y a circular por un complejo entramado social que se compone de relaciones de reciprocidad, de afinidad, de alianza, de amor, de solidaridad, pero también, de violencia física y simbólica que agrega una cuota más de castigo a la ya impuesta de la privación de la libertad ambulatoria. En cuanto al discurso autojustificador en la construcción del orden social carcelario, tiene que ver con la lucha por ser reconocidas y respetadas como "buenas madres" a pesar del dictamen judicial. Incluso así hubieran asesinado a sus propios hijos.

En este sentido, la maternidad continúa siendo un dispositivo de disciplinamiento (FOUCAULT, 1998). No solo las agentes penitenciarias encausan los sentidos del deber ser de las mujeres, cuando hacen deferencias y otorgan tratos diferenciales a quienes consideran "buena madre", sino que las propias internas comparten estos sentidos, llevándolos a un extremo aún más peligroso. Por este motivo, las evaluaciones morales y los sentidos formales de un tipo de maternidad se vuelven de vital importancia dentro de la cárcel al colaborar en la definición de una trayectoria carcelaria que será más o menos humana. Es decir, una estadía en la cárcel de la que se podrá disponer de recursos materiales o no, de amistades o enemistades, de apoyo emocional o persecución y hostigamiento (como suele suceder con aquellas mujeres detenidas por delitos de felicidio).

Pero, en este ambiente paradójico que se crea en prisión, los sentidos formales sobre la maternidad también se recrean y se redefinen para dar nacimiento a formas alternativas. Así, tras resolver la disyuntiva sobre mantener o no a los hijos dentro de la cárcel, la maternidad en el encierro se convierte en una maternidad colectiva o compartida y, como tal, interpela la definición hegemónica de la maternidad como hecho individual y natural (HIRCH y AMADOR OSPINA, 2011). Madres y tías colaboran en la crianza de los niños y, si bien en última instancia nunca es posible resolver qué es lo mejor para ellos, la cárcel se convierte en un espacio real y posible de socialización y desarrollo.

Pero el sentido alternativo de una maternidad compartida, también 
está permeado por aquellos otros sentidos formales, de los que se habló al principio, porque las mujeres encuentran en los hijos de otras, la forma de mostrar sus habilidades maternales. Sobre todo en su condición liminar: no siempre pueden demostrar que han sido o son buenas madres por estar presas. Pero estas alianzas estratégicas respecto del cuidado de los niños en la cárcel terminan por reforzar la responsabilidad genérica femenina, revalidando relaciones de desigualdad preexistente a la detención. Es por eso que la invisibilización y naturalización de esta ética y construcción de una moralidad especifica ligada al cuidado de los niños en prisión, garantiza la continuidad de su ejecución por parte de las mujeres (ESTEBAN, 2003). De aquí la importancia de contribuir a su desnaturalización en los diversos contextos.

La maternidad en prisión deja al descubierto una de las características paradojales de la cárcel: por un lado, la categoría impuesta de "buena madre", a la que finalmente quedan sometidas todas las mujeres, se refuerza en el encierro a puño y punta de "faca", estableciendo ordenamientos y jerarquizaciones entre las detenidas. En síntesis, se trata de las posibilidades y las tensiones supuestas en las alternativas de estas maternidades colectivas que, en simultáneo, hablan de relaciones de afecto, de amor y de solidaridad pero también de continuas y subrepticias legitimaciones del modelo tradicional de maternidad (y de mujer), que, en definitiva, queda jerarquizado como el modelo ideal, cuando, ejemplarmente, ellas hacen notar cómo los bebés y niños que están en la cárcel "con la tía no lloran".

\section{Referencias}

BANCIN, Gabriela; GEMETRO, Florencia.

(2011). Comaternidad: experiencias, autodefiniciones y derechos. En: Karina Felitti (Comp.); Madre no hay una sola. Experiencias de maternidad en la Argentina. Buenos Aires: Ediciones Ciccus. p.93-109.

CAIMARI, Lila.

(2007). Entre la celda y el hogar. Dilemas estatales del castigo femenino (Buenos Aires, 1890-1940). Nueva Doctrina Penal, Vol.3, N²2, p.427-450.
D’ANTONIO, Débora.

(2011). Políticas de desarticulación de la subjetividad sexual y de género practicadas en la cárcel de Villa Devoto durante la última dictadura militar argentina (1976- 1983). Revista Estudios, № 25, enero-junio, p.159174.

DURKHEIM, Émile.

(1993). Escritos selectos. Introducción y selección de Anthony Giddens. Buenos Aires: Nueva Visión. 
ESTEBAN, Mari Luz.

(2003). Cuidado y salud: costes para la salud de las mujeres y beneficios sociales. Género y cuidados: algunas ideas para la visibilización, el reconocimiento y la redistribución. En: SARE 2003; Cuidar cuesta: costes y beneficios del cuidado. Estado Español: Emakunde/ Instituto Vasco de la Mujer; España: Euskadi.

FONSECA, Claudia.

(1995). Caminos de Adopción. Buenos Aires: Eudeba.

FOUCAULT, Michel.

(1992). Microfisica del poder. Madrid, La Piqueta.

(1998). El sujeto y el poder. Revista mexicana de sociología, Vol. 50, № 3, p. 3-20.

HIRSCH, Silvia y AMADOR OSPINA, Marcela.

(2011). La maternidad en mujeres jóvenes guaraníes del norte argentino. Encrucijada de la familia, la salud pública y la etnicidad. En Karina Felitti (Comp.); Madre no hay una sola. Experiencias de maternidad en la Argentina, Buenos Aires: Ediciones Ciccus, pp. 155-177.

\section{KALINSKY, Beatriz.}

(2011). Hijos de la cárcel. Maternidad y encierro. En Karina Felitti (Comp.); Madre no hay una sola. Experiencias de maternidad en la Argentina. Buenos Aires: Ediciones Ciccus. p. 211-235.

(2007). El felicidio. Algunos recaudos conceptuales. Nómadas. Revista critica de ciencias sociales y jurídicas. Vol. 16, №2, p.301-313.

(2006). Los usos de la prisión. La otra cara de la institucionalización. El caso de las mujeres encarceladas. Ley, Razón y Justicia. Revista de Investigaciones en Ciencias Jurídicas y Sociales, Año 7, N 10, p.181-204.

KALINSKY, Beatriz; CAÑETE, Osvaldo.

(2010). Madres Frágiles. Un viaje al infanticidio. Buenos Aires: Biblos.

LAMA, Martha.

(1986). Feminismo y maternidad. En: FEM, Diciembre - Enero, México, p.152-169.
MAUSS, Marcel.

(1979). A expressão obrigatória dos sentimentos. En: Cardoso de Oliveira, Roberto (Org.); Mauss. San Paulo: Editora Ática. p.147153.

MONTALVO CEPEDA, María Augusta.

(2007). El ejercicio político de la maternidad en la cárcel de mujeres de Quito: Testimonios y perspectivas. Tesis de maestría en el Área de Estudios Sociales y Globales, presentada a Universidad Andina Simón Bolívar. Sede Ecuador.

MORENO, Amparo.

(2000). Los debates sobre la maternidad. En: Carmen Fernández Montraveta; Pilar Monreal Raquena; Amparo Moreno; Pilar Soto Rodríguez (Comp.); Las representaciones de la maternidad. Madrid: Ediciones de la Universidad Autónoma de Madrid. p.1-9.

NARI, Marcela.

(2004). Políticas de maternidad y maternalismo político (Buenos Aires 1890-1940). Buenos Aires. Biblios.

NOEL, Gabriel.

(2011). Cuestiones disputadas. Repertorios morales y procesos de delimitación de una comunidad imaginada en la costa atlántica bonaerense. Revista Publicar en Antropología y Ciencias Sociales, Año IX, № XI, p.99-126.

PALMA CAMPOS, Claudia.

(2011). Delito y sobrevivencia: Las mujeres que ingresan a la cárcel del buen pastor en Costa Rica por tráfico de drogas. Anuario de estudios centroamericanos, Vol. 37, p.245-270.

SÁNCHEZ, Paula; ISNARDI, Virginia; GIORDANO, Paula y DE ISLA, María.

(2011). Mujeres Penitenciarias. Una experiencia de trabajo y reflexión. Buenos Aires: Pasart.

SCHEPER-HUGHES, Nancy.

(1997). La muerte sin llanto. Violencia y vida cotidiana en Brasil. Barcelona. Ariel.

SIMPSON, Sally.

(1990). Feminist theory, crime and justice. Readings in contempory criminological theory. Boston: Northeastern University Press. 
SMART, Carol.

(1994). La mujer del discurso jurídico. En: Elena Larrauri (Comp.); Mujeres, derecho penal y criminología Madrid: Siglo XX. p.167-190.

\section{TISCORNIA, Sofía}

(2004). Entre el honor y los parientes. Los edictos policiales y los fallos de la Corte Suprema de Justicia. El caso de "Las Damas de la calle Florida" (1948-1958). En: Sofía Tiscornia et. al. (Comp.); Burocracias y violencia. Estudios de Antropología Jurídica. Buenos Aires: Antropofagia, p.13-62.
ZIGON, Jarret.

(2007). Moral breakdown and the ethical demand. A theoretical framework for anthropology of moralities. Anthropological Theory, Vol. 7, $\mathrm{N}^{\circ} 2$, p.131-150.

\section{Recebido em}

outubro de 2014

Aprovado em agosto de 2015 